\title{
CARTAS DE JUAN NATALICIO GONZÁLEZ PARA O SEU MESTRE JUAN O'LEARY; A AUTONOMIA LITERÁRIA E POLÍTICA DO DISCÍPULO
}

\author{
JUAN NATALICIO GONZÁLEZ'S LETTERS TO HIS \\ MASTER JUAN O'LEARY: THE LITERARY AND POLITIC \\ AUTONOMY OF THE FOLLOWER
}

\author{
Marcela Cristina Quinteros ${ }^{1}$
}

\section{RESUMO}

Juan Natalicio González foi um intelectual paraguaio que, identificado com o revisionismo histórico e filiado ao Partido Colorado, teve um papel central na difusão desse revisionismo além das fronteiras de seu país através das diversas atividades que exerceu ao longo das primeiras décadas do século XX, até sua morte no México em 1966. Aqui serão analisadas as missivas que González endereçou para seu grande mestre, o principal referente do revisionismo histórico paraguaio, Juan Emiliano O'Leary, nos primeiros anos de sua vida intelectual e política. O objetivo desta análise é identificar os projetos literários, editoriais e políticos de González nessa fase e, ao mesmo tempo, compreender o vínculo que o unia a Juan O'Leary. A leitura das cartas que o discípulo González enviou para seu mestre na década de 1920 permitiu identificar que a literatura, o jornalismo e o trabalho editorial foram ferramentas utilizadas por González para atingir suas ambições políticas que, basicamente, orientavam-se a assumir a liderança do Partido Colorado, para depois conquistar o poder. As missivas, em sua maioria escritas enquanto morava em Buenos Aires, revelam o modo de fazer política de González dentro e fora do Paraguai já que, por um lado, manteve um contato permanente com o partido e participava nas decisões editoriais dos jornais partidários e, por outro lado, interferiu diretamente na vida das associações de paraguaios em Buenos Aires. Por último, elas possibilitam identificar a autonomia do discípulo em relação a seu mestre para estabelecer seus próprios projetos. Este artigo tem origem numa pesquisa de doutorado sobre a trajetória de Juan Natalicio González como um intelectual latino-americano plural.

Palavras-Chave: Juan Natalicio González. Revisionismo Histórico Paraguaio. Juan O'Leary.

1 Doutoranda em História. Universidade de São Paulo, Brasil. E-mail: mquinteros@usp.br. 


\begin{abstract}
Juan Natalicio González was a Paraguayan intellectual, identified with the historical revisionism and the Colorado Party. He played a central role in spreading this historical revisionism over his country's frontiers, through of different activities during the early decades of the XX century, until his death in 1966. In this article, we will examine the González's letters to his master Juan Emiliano O'Leary, the main referent of Paraguayan historical revisionism, those were written in the first years of his intellectual and political life, during the 1920's. The goals of this text are the study of the literary, editorial and political projects of Natalicio González and the understanding of the relation between González and O'Leary. The reading of these letters enables us to recognize that the literature, the journalism and the editorial work were tools used by González to achieve his political ambitions. These letters were elaborated when González lived in Buenos Aires and they show the way he practiced his politics inside and outside Paraguay. Finally, these sources aid to identify the autonomy of González to decide his own projects. This article is part of an investigation about the Juan Natalicio González's trajectory as a Latin-American plural intellectual.
\end{abstract}

Keywords: Juan Natalicio González. Paraguayan Historical Revisionism. Juan O’Leary. 


\section{Introdução}

Juan Natalicio González (1897-1966) foi ensaísta, jornalista, editor, político, embaixador e diretor das revistas por ele criadas, Guarania, América Económica e Eutaxía, além de estar filiado à Associação Nacional Republicana (ANR), conhecida como Partido Colorado. Nascido no interior do Paraguai, González mudou-se para a capital após terminar o segundo grau, e ali participou ativamente dos debates calorosos que se sucederam nas primeiras décadas do século XX. Embates que alcançaram seu ápice em três momentos: em 1920, com o cinquentenário da Grande Guerra - como é denominada a Guerra da Tríplice Aliança pela historiografia paraguaia -, deu-se a discussão em torno da recuperação da figura de Solano López; em 1926, ano do centenário do nascimento de López, este debate aprofundou-se com total virulência; e entre 1932-1935, a raiz da Guerra do Chaco, a história "revisada" convocou, uma vez mais, o interesse de lopiztas e antilopiztas, estendendo o embate sobre as origens da nacionalidade e, portanto, da identidade.

González participou em diferentes âmbitos da vida cultural e política paraguaia. Sua produção escrita é fecunda. Aos ensaios somam-se numerosos artigos em jornais e revistas; a produção epistolar com intelectuais paraguaios e latino-americanos; a criação e direção da revista Guarania - que embora intermitente e itinerante, foi sua revista de mais longa duração -; a publicação de livros de outros autores através de suas editoras - Editorial de Indias e Guarania -, alguns com extensos prólogos de sua autoria. Sua participação na vida política nacional transitou pelos cargos de deputado, ministro, presidente e embaixador. Em diferentes momentos morou fora de seu país nos quais forjou encontros e vínculos com pensadores latino-americanos. Como filiado da ANR, participou ativamente na elaboração das bases ideológicas do partido. Seguindo os lineamentos de Juan O'Leary, principal referente do revisionismo histórico paraguaio, colaborou na reconstrução da memória nacional recuperando a figura de Solano López, condenando o liberalismo e resgatando o vernáculo, que identificava com a cultura guarani.

Juan Natalicio González também incursionou na vida política militando no Partido Colorado e assumindo cargos como deputado (1928), ministro da Fazenda (1945-1948), presidente do país (1948-1949) e 
como embaixador no Uruguai (1945) e no México (1956-1965). Na década de 1940, impulsionou a criação do Guión Rojo, sua facção política no seio da ANR, e se impôs como candidato presidencial do partido para as eleições convocadas para 1948. Tanto González quanto o Guión Rojo foram - e continuam sendo - questionados pela violência empregada para obter resultados políticos favoráveis.

Para conhecer a trajetória de Juan Natalicio González é possível uma primeira aproximação através da leitura de suas biografias, autobiografias e epistolários. Os textos oferecem representações diferenciadas segundo a intencionalidade dos autores, o momento em que foram escritos, as editoras que os publicaram. Aqui foi escolhido analisar o epistolário de Juan Natalicio González como exemplo de uma escrita autobiográfica ou escrita de si.

Tanto da leitura de textos de González quanto de considerações de amigos e/ou intelectuais com os quais ele se correspondia, se desprende que o escritor paraguaio tinha um especial interesse em preservar tudo o que produzia ou recebia, como cartas, presentes, fotografias, folhetos e caricaturas, provenientes de membros dos diferentes círculos de sociabilidade que integrou ao longo de sua vida, em diferentes momentos e em diferentes espaços (geográficos, literários e/ou políticos).

Segundo o testemunho dos amigos mais próximos (Víctor Morínigo, Washington Ashwell, Efraín Enríquez Gamón), antes de seu decesso no México, o projeto de González era organizar sua biblioteca e seu arquivo pessoal para levá-los consigo em seu regresso ao Paraguai em 1966 (ASHWELL, 2004; ENRÍQUEZ GAMÓN, 1982). Com a morte súbita do intelectual paraguaio poucas horas antes de embarcar para Assunção, o material que já tinha sido encaixotado, desapareceu.

Alguns textos inéditos de González foram recuperados e publicados posteriormente por Morínigo, como é o caso de suas memórias, sob o título "Vida e paixão de uma ideologia" (GONZÁLEZ, 1982). Outros documentos, como a correspondência de González, ainda que fragmentária, foi consultada em arquivos de intelectuais com os quais manteve um contato epistolar. Aqui foi escolhido analisar as missivas enviadas ao intelectual paraguaio Juan O'Leary, durante a década de 1920. 
Juan Emiliano O'Leary (1879-1969), considerado o pai do revisionismo histórico paraguaio e reivindicado como o historiador oficial do país durante o governo de Alfredo Stroessner, foi o principal referente na recuperação da figura de Solano López como herói nacional, na reinterpretação da derrota bélica de 1870 como uma 'epopeia nacional' e no resgate do povo paraguaio como o 'invicto vencido' (BREZZO, 2014).

A primeira batalha da reescrita da história aconteceu a começos do século XX, a partir dos debates jornalísticos entre Juan O'Leary e o liberal Cecílio Báez. Tendo ganho esta fase, a segunda batalha iniciouse no cinquentenário do fim da Guerra da Tríplice Aliança, em 1920, também através da escrita, quer jornalística, quer ensaística, mas não já com o objetivo de um debate eminentemente intelectual e sim com o claro propósito de instalar a disputa na opinião pública.

Esta batalha foi a mais longa e sistemática, tendo as mais diversas estratégias, desde a troca de nomes de ruas e bairros até a construção de monumentos e o traslado dos restos de Solano López ao Panteão Nacional dos Heróis em 1936. ${ }^{2}$ Não há dúvidas do papel central que coube a O'Leary na liderança deste processo, mas figuras como as de González foram essenciais não somente para a apresentação de inúmeros artigos jornalísticos e ensaios, senão, também, através da ação política como militantes do Partido Colorado e como parlamentares no Congresso Nacional.

O labor intelectual de González neste sentido surgiu com suas publicações e a criação de uma editora, colaborando ativamente na reescrita da história. A partir da troca epistolar com O’Leary é possível identificar o modo como relacionou-se com seu mestre e o papel que assumiu nesse processo histórico de consolidação e difusão do revisionismo paraguaio, dentro e fora do país. Como contrapartida,

\footnotetext{
${ }^{2}$ Em 1863, Solano López decidiu a construção de um oratório para a Virgem de Assunção, ficando interrompida por conta da guerra da Tríplice Aliança iniciada dois anos mais tarde. A construção seria concluída só em 1936, mas como Panteão dos Heróis, com a exumação e traslado dos restos de Solano López desde Cerro Corá até a cidade de Assunção. O lugar foi erigido no centro histórico da capital paraguaia, no lugar mais alto, de frente para o rio Paraguai e converteu-se no lugar físico e simbólico de permanentes disputas pela construção e apropriação da memória nacional. Até o presente, continuam se apresentando projetos para a inclusão de restos de excombatentes da Guerra do Chaco como heróis nacionais, ao mesmo tempo em que o lugar passa por sucessivas e prolongadas reformas no local.
} 
O'Leary tinha em seu discípulo um fiel assessor e defensor de sua imagem, além de seus ideais.

Contrariamente ao que desejaria o próprio O’Leary, sua história pessoal dista muito de ser uma história de vida linear e coerente, razão pela qual teve que retomar e rebater seus escritos de juventude para dar a coerência necessária a seu lopizmo fervoroso da maturidade. Até hoje, seus críticos baseiam algumas de suas objeções no fato de O'Leary ter sido anti-lopizta em suas primeiras incursões literárias.

O'Leary era muito ligado à sua mãe que, viúva do primeiro marido morto na Guerra da Tríplice Aliança - e condenada a migrar para as montanhas com seus três pequenos filhos - dos quais dois teriam morrido de fome - por ter falado contra a guerra, casou-se em segundas núpcias com Juan O'Leary, um comerciante argentino instalado em Assunção após o triunfo dos aliados (BREZZO, 2011).

Juan Emiliano O'Leary, era o menor de quatro filhos deste segundo matrimônio. O sofrimento da mãe, causado pela miséria e a perda dos filhos, teria levado O'Leary a escrever aos 18 anos que ela "tinha perdoado ao tirano, que tão brutalmente te tratou. Mas eu não o perdoo. Eu o esqueço" (BREZZO, 2011, p.22). Segundo Liliana Brezzo, O'Leary assumiu publicamente uma autocrítica vinte anos mais tarde, quando publicou no jornal colorado Pátria que "não sou eu quem fala ali. É o entorno que gravita em minha alma infantil" (BREZZO, 2011, p.22-23). Esta seria apenas uma das declarações de O'Leary na construção de seu próprio prestígio como o historiador do Paraguai e pai do revisionismo histórico.

Quando do traslado dos restos de Solano López para o Panteão, estando em Paris, O'Leary escreveu em seu diário pessoal que "López foi minha bandeira, porque ele representa a nossa soberania atropelada e a resolução de sermos somente paraguaios. Poderão me esquecer, mas aí ficam minhas obras e minha propaganda que, desde 1900, enche as páginas da imprensa nacional" (BREZZO, 2011, p.16).

O'Leary foi um grande estrategista na construção de seu próprio prestígio, teve um grupo de seguidores, como González, que contribuiu e muito nesse objetivo. Desse modo, militantes e escritores “disciplinados" como González, também, ajudaram na consolidação do lopizmo como parte de um mesmo processo. Algumas das ações para tal 
efeito podem ser identificadas a partir da análise da correspondência entre ambos.

As epístolas de González a O’Leary pertencem ao acervo pessoal deste último, preservadas pelo Arquivo da Biblioteca Nacional do Paraguai. Aqui foram consultadas 33 cartas, escritas entre 1920 e 1927. Para o mesmo período só foram encontradas cópias de duas cartas de O’Leary para González.

\section{O discípulo e o mestre}

Para Ângela de Castro Gomes, o emprego das cartas como fonte/objeto da escrita de si deve considerar que elas constituem "um lugar de sociabilidade fundamental e revelador da dinâmica do campo cultural de um dado período" (GOMES, 2004, p.52). Para a autora, as cartas, assim como os diários e as memórias, são textos íntimos. Mas no caso das cartas, o que é escrito "só pode ser apreendido em função de um 'outro", que é quem recebe e se torna seu proprietário (GOMES, 2004, p.53). Deste modo, a autora alerta sobre os diferentes tipos de missivas segundo o relacionamento do autor com o destinatário, o que está diretamente vinculado ao "lugar social" de quem escreve, ou seja, à posição que ocupa no campo intelectual e político.

Gomes identifica, basicamente, dois tipos de correspondência: um está integrado pelas cartas que servem como instrumento de construção de redes, enquanto que o segundo está composto por missivas de amizade intelectual, de caráter mais informal e interessante pela evocação de sentimentos, além da troca de ideias e favores (GOMES, 2004, p.54).

As cartas que González enviou a O’Leary, objeto deste artigo, inscrevem-se no segundo tipo de epístolas segundo a classificação de Gomes. Todas elas têm o mesmo encabeçamento respeitoso e carinhoso - "Querido Dom Juan" - mas que, ao mesmo tempo, evidencia a proximidade do "grande discípulo" com seu "grande mestre", mantendo a formalidade dada pelo uso do pronome usted. Sem perder a hierarquia entre discípulo e mestre, a intimidade é confirmada pela reciprocidade de favores - tais como o envio de revistas e livros, recomendações, remédios, tinta, papel entre outros. 
Há um permanente reconhecimento da liderança de O'Leary por parte de González, mas sem perder sua autonomia para fazer críticas aos textos de O'Leary, sugestões para a ação política; se explicar pela interrupção da periodicidade na troca epistolar. Há um reconhecimento de O'Leary como fundador do movimento revisionista; mas, González soube preservar sua individualidade diante do mestre para estabelecer suas próprias metas e critérios para a ação literária, editorial e política.

O período em que González escreveu este grupo de cartas para O'Leary corresponde à fase de grandes mudanças e definições em sua vida: criou uma revista, saiu do Paraguai para morar em diversos países, fundou sua editora, voltou para sua pátria onde foi eleito deputado e casou-se com Lydia Frutos. Ao mesmo tempo, foi o momento mais intenso na luta pela reivindicação de Solano López.

Todos estes acontecimentos da vida privada e pública de González surgem diretamente ou indiretamente na escrita epistolar. A pesar da intimidade criada pelo vínculo afetivo com O'Leary e da relativa distância dada pela relação discípulo-mestre, manifestam-se tensões no discurso escrito de González como expressão de seu pensamento, tensões inerentes a toda correspondência porque ela "se caracteriza pela interrupção, pela exigência de continuidade, pela pausa entre uma e outra carta, pela obsessão com as cartas extraviadas e pela angústia do corte" (PIGLIA, 2006, p.46).

Se as interrupções e as angustias são parte de toda troca epistolar, elas aparecem mais explícitas na correspondência que Gomes identifica como missivas de amizade intelectual, na qual a proximidade emocional é maior, como acontece na correspondência que González endereçou a O'Leary no início de sua vida intelectual e política. Tais cortes e preocupações são diferentes segundo o momento da escrita e segundo o destinatário das cartas.

As cartas de González a O'Leary comprovam o percurso percorrido pelo primeiro segundo seus biógrafos, salvando algumas pequenas diferenças nas datas. Por exemplo, após a criação da revista Guarania em Assunção em 1920, trasladou-se a Buenos Aires como funcionário da editora Monte Domecq. As cartas datadas na capital argentina situam-se entre 1921 e novembro de 1924. Uma carta de dezembro de 1924 foi escrita a bordo do buque que o levaria até a Venezuela para a 
execução de um projeto editorial encomendado pela mesma editora. Outra carta de outubro de 1925 foi escrita a bordo do buque que o traria de volta da Europa para Assunção e, a última foi escrita em Assunção em agosto de 1927.

A maioria das cartas - 28 no total - foi escrita enquanto González morou em Buenos Aires. Entretanto, o destinatário O’Leary também transitou por diversos lugares ao longo do período considerado, dividido entre Assunção e a Europa, continente onde desempenhou-se como embaixador em diferentes momentos de sua vida (ADEP, 2011, p.73).

Há elementos que se repetem em praticamente todas as missivas. Tais como, a troca intelectual, a preocupação pelos acontecimentos políticos tanto na cena política nacional quanto no interior do Partido Colorado, o estabelecimento de contatos e intercâmbios com intelectuais de outras latitudes, a troca de informações sobre amigos e adversários, e o relato das tarefas intelectuais e políticas executadas e/ou projetadas por González.

As duas primeiras cartas foram escritas em Assunção, entre 1920 e 1921, e iniciam-se com a preocupação de González com tudo o que acontecia no Partido Colorado ao informar sobre as novas autoridades, as condições de publicação no jornal Pátria, principal órgão jornalístico do partido, ao oferecer detalhes sobre as atividades e a saúde dos amigos, além do projeto de elaborar um plano para deslocar os adversários da cúpula partidária (Cartas de González a O'Leary, de 16/01/1920 e de 23/02/1921). O conteúdo de ambas as cartas se completa com o reconhecimento de González sobre a qualidade poética de O'Leary e o comentário de um artigo do escritor venezuelano Laureano Vallenilla Lanz (1870-1936), publicado no jornal Pátria.

O grupo de epístolas escritas em Buenos Aires evidencia a tensão entre o desejo de manter uma periodicidade e as interrupções "involuntárias" que impediam a sequência programada no envio das cartas. A primeira delas é uma exposição de desculpas pelas quais González não teria conseguido até aquele momento escrever para O'Leary, contando-lhe sobre sua mudança e seu estabelecimento na urbe portenha (carta de González a O’Leary, de 11/06/1921). Nessa mesma carta, González fazia questão de mostrar toda sua gratidão a O'Leary por ter facilitado seu desenvolvimento e reconhecimento intelectual. Neste mesmo plano 
de gratidão, o estilo da escrita revela a necessidade de render conta de todos seus atos, informando-lhe onde morava, que tipo de trabalho realizava na Monte Domecq e sobre os primeiros contatos com intelectuais paraguaios que naquele momento transitavam por Buenos Aires.

Porém, já a partir da segunda carta, surge um "Natalicio" mais seguro de si, com a autonomia e a confiança de quem se dirige a um igual. Era um "Natalicio" que não perdia de vista que escrevia a seu mestre, mas este era um aliado intelectual e político que podia brindar-lhe ajuda intelectual, favorecer a publicação e distribuição de artigos e livros; era o "colega" a quem sugeria leituras. Esse "Natalicio" assinava as cartas só com seu segundo nome, mostrando grande carinho pelo "amigo" O'Leary, mas que referia-se aos "outros" amigos no diminutivo. ${ }^{3}$ Talvez, González tentasse evitar o fato de aparecer como arrogante ao usar expressões de carinho e deferência pelos Tomasitos e Morenitos, mas sugerindo certa hierarquização entre intelectuais líderes - como O’Leary e ele próprio - e os “outros”, nomeados em forma diminutiva.

González surgia com uma forte autoestima, capaz de se inserir no meio intelectual portenho, de levar adiante seus projetos e de mostrar ao mundo a fortaleza do sangue guarani. Em janeiro de 1922 dizia:

En cuanto a mí, no hay que preocuparse. Ya voy conociendo el ambiente bonaerense y no hay tempestad que pueda derribarme. Si pierdo mi puesto, casi saldría beneficiado, pues hay que convenir que Buenos Aires no es ciudad para empleados. Para hacerse de dinero aquí hay que trabajar uno por su propia cuenta, no depender de nadie en una palabra, ideal que estoy empeñado

\footnotetext{
${ }^{3}$ O personagem mais citado é o arquiteto Tomás Romero Pereira (1886-1982), a quem referia-se como Tomasito. Onze anos mais velho, Romero Pereira e González conheceram em Buenos Aires nos primeiros anos da década de 1920. Em dezembro de 1924, empreenderam juntos a viagem que os levaria até a Venezuela para a confecção de um livro informativo sobre o país, encomendado pela editora Monte Domecq. Ambos continuaram juntos rumo à França onde, além de compartilhar a mesma moradia, fundaram a Editorial de Indias. Segundo Efraín Enríquez Gamón, os amigos se separaram quando Romero Pereira apaixonou-se por uma bailarina russa e decidiu acompanha-la até Moscou. Ambos se reencontrariam uma década mais tarde, em Buenos Aires. A pesar de pertencerem ao mesmo partido, respondiam a linhas internas contrárias (ENRÍQUEZ GAMÓN, 2012, p.117-141).
} 
en realizar y creo firmemente que no pasará este año sin que salga con la mía (Carta de González a O'Leary, de 24/01/1922). ${ }^{4}$

González referia-se à iniciativa de abrir sua própria editora, empreendimento que não só permitiria a publicação de seus textos senão que também beneficiaria o grupo de sociabilidade ao qual pertencia e que brigava por uma mudança na escrita da história paraguaia e pela renovação do Partido Colorado.

O projeto de criar uma editora era extremamente ambicioso pois permitiria a divulgação de autores revisionistas, sem censuras. Contribuiria, também, para a revisão da história nacional e seu alcance iria além de publicações periódicas como a revista Guarania ao favorecer a renovação do quadro de escritores com a incorporação das “jovens promessas”. Além disso, os escritores paraguaios não ficariam à mercê da tirania das editoras portenhas que, segundo González, praticamente monopolizavam as publicações no Paraguai. Para ele, a correspondência entre a renovação da intelectualidade paraguaia e a renovação dos dirigentes do partido era parte de um mesmo processo. Portanto, poder decidir quais autores e quais temas deviam ser publicados contribuiria a esse processo de renovação intelectual e partidária.

Seu livro Cuentos y Parábolas foi publicado pela Monte Domecq; porém, González aspirava que ele inaugurasse:

Mi célebre editorial de que le hablé tantas veces. Ya ve que la tenacidad elevada al grado heroico suple a veces a la falta de dinero... No descansaré, no reprimiré fatigas ni trabajos hasta realizar esta quimera mía para que todos nosotros podamos editar en adelante nuestros libros, sin renunciar a los legítimos beneficios de nuestra labor literaria a favor de editores inescrupulosos. El mercado paraguayo es una gran base para

\footnotetext{
${ }^{4}$ Em dezembro de 1924, manifestava que não seria um barco que o derrubaria com tontura já que "meu forte sangue guarani tem me imunizado contra enjoos" (Carta de González a O'Leary, de 12/12/1924). A autoconfiança de González era tão sólida em seus vinte e tantos anos que considerava ter o critério suficiente para saber qual de seus escritos deveriam ser publicados e quais não. Em 1922, confessava ter terminado de escrever sua melhor novela e de ter orgulho de ter criado algo enquanto outros só sabiam destruir. González referia-se à Guerra Civil de 1922 na qual enfrentaram-se facções opostas do Partido Liberal (Carta de González a O’Leary, de 31/10/1922).
} 
empresas de esta índole (Carta de González a O’Leary, de 24/01/1922). ${ }^{5}$

Para González, seu projeto editorial tinha fins intelectuais e políticos, mas sem descuidar o aspecto econômico. Portanto, na correspondência dirigida a O’Leary surge, também, o Natalicio González empresário, conhecedor das condições de produção e comercialização do mercado editorial.

Para iniciar a editora, em 1922, González revelava ter poupado os recursos necessários para abri-la (carta de González a O'Leary, de 24/01/1922). Porém, o grande sonho teve que esperar até 1925 quando, estabelecido em Paris e em sociedade com Tomás Romero Pereira, abriu a Editorial de Índias. ${ }^{6}$

González reconhecia nas cartas que o aprendizado sobre o trabalho editorial foi adquirido nos anos em que tinha sido funcionário de editora Monte Domecq. ${ }^{7}$ González via em seu dono, um homem bom; mas também enxergava nele o que não queria imitar, considerando-o um mal administrador e nada mais que um comerciante. Pelo contrário, González pretendia ser editor para favorecer a publicação de autores e temas marginalizados pelas grandes editoras. Seu interesse como empresário estaria limitado só a lograr a viabilidade de sua empresa e não pelo lucro em si (carta de González a O’Leary, de 26/08/1922).

Na última carta, de 1927, González referia-se aos percalços da tarefa editorial. Ele encontrava-se de regresso em Assunção e em plena campanha parlamentar para a construção de um monumento ao

\footnotetext{
${ }^{6}$ Segundo Enríquez Gamón, Natalicio González teria lhe manifestado em 1962 que, seu pai continuava cortando madeira no monte localizado entre Caaguazú e Villarrica, para contribuir aos "entretenimentos livrescos" do filho (ENRÍQUEZ GAMÓN, 2012, p. 125). Porém, segundo um dos biógrafos de Juan Natalicio González, seu pai teria falecido em 1914, muito antes de González iniciar suas atividades editoriais (GONZÁLEZ Y CONTRERAS, 1951).

7 A Editora Monte Domecq foi fundada em 1910, em Assunção, por Ramón Monte Domecq (Assunção, 1883-1970). Ela começou com a publicação de reproduções iconográficas da história paraguaia, e continuou com publicações de alta qualidade fotográfica sobre a história do Paraguai. A partir de 1916, deu início a publicações deste tipo sobre outros países latino-americanos (Brasil, Peru, Argentina, Venezuela, etc.). Para isto, no início da década de 1920, trasladou-se à cidade de Buenos Aires, contando com os serviços de Natalicio González e de Tomás Romero Pereira, entre outros. As atividades editoriais foram continuadas pelos sucessores de Ramón Monte Domecq, estendendo-se ao longo de todo o século XX (SERVÍN GAUTO, 2001).
} 
Marechal López. Já era casado com Lydia Frutos e sua editora tinha superado os primeiros dois anos de vida.

Alguns desses obstáculos referiam-se à falta de máquinas e papel adequados para a impressão de livros de maior qualidade no Paraguai, dado assinalado nas cartas anteriores, explicando o porquê da decisão de imprimir na França (carta de González a O’Leary, de 08/07/1922). Nesta mesma carta, González falava da publicação de um álbum sobre o Paraguai, cujo desafio aceitou:

Por indicación del Presidente de la República, no por iniciativa mía, tendré que hacerlo con mis propios medios, sin ayuda oficial, porque yo me niego rotundamente a ultrajar a mi país en un libro llamado a enaltecerlo a los ojos de los extraños (carta de González a O'Leary, de 01/08/1927). ${ }^{8}$

Este álbum foi publicado em 1929, pela Editorial de Índias, em Paris, sob o título "O Paraguai Contemporâneo". González compartilhava sua autoria com Pablo Max Ynsfrán. ${ }^{9}$ Chama a atenção o fato de González fazer referência à origem dos recursos dois anos antes de sua publicação porque o acontecimento seria motivo de intermináveis polêmicas. Após o golpe de Estado de 1949, que o tirou da presidência do Paraguai, González foi acusado de ter recebido dinheiro do Estado para a publicação deste livro em forma ilegal. Ele tentou se defender e justificar contra as denúncias de corrupção até o fim de seus dias, sem muito sucesso, em sua autobiografia "Vida e Paixão de uma Ideologia".

A editora era, para González, um instrumento para promover autores pouco publicados e já desaparecidos (como alguns cronistas do período colonial ou filósofos gregos pelos quais González sentia intensa admiração), ou bem autores contemporâneos lopiztas como Juan O’Leary, Fulgencio Moreno e Arsenio López Decoud. O objetivo não era só publicar seus textos, senão também biografias sobre tais autores

\footnotetext{
${ }^{9}$ Pablo Max Ynsfrán (1894-1972) foi um jornalista, ensaísta e poeta paraguaio que participou no governo do General José Félix Estigarribia (1939-1940) e desempenhouse como embaixador nos Estados Unidos. Durante o governo de Higinio Morínigo (1940-1948) radicou-se definitivamente nos Estados Unidos, onde ministrou a disciplina História Hispano-americana na Universidade de Austin (Texas) até sua aposentadoria. Suas principais obras, El Paraguay Contemporáneo (1929) e La expedición norteamericana contra el Paraguay (1958) foram publicadas pelas editoras de González (BENÍTEZ, 1986).
} 
com a clara intencionalidade de promovê-los e, desse modo, promover também seus textos. ${ }^{10}$

A promoção do grupo devia ser feita também em âmbito internacional, estabelecendo os vínculos necessários com diplomatas e/ou intelectuais de outros países que possibilitassem a publicação de textos de escritores paraguaios fora das fronteiras do país e, se possível, em outras línguas.

Este objetivo foi particularmente perseguido enquanto González morou em Buenos Aires. Obviamente, sendo seu destinatário, a maioria das cartas faz referência a cuidar da imagem de O'Leary e só ocasionalmente menciona outros autores. Por meio da defesa internacional do O'Leary lopizta, do intelectual já maduro que teria salvado Solano López das "injustiças" de uma história escrita pelos liberais paraguaios, González contribuiria à difusão do revisionismo histórico paraguaio.

A primeira atitude de González foi a de garantir a publicação de ensaios de O'Leary pela Monte Domecq (carta de González a O'Leary, de 24/09/1921). Em segundo lugar, trabalhou intensamente promovendo encontros com intelectuais-diplomatas europeus que pudessem intermediar na publicação de O'Leary em italiano ou francês (carta de González a O’Leary, de 26/04/1922). Uma terceira atitude foi mostrar sua preocupação com a integridade física do mestre em momentos de conflito armado no Paraguai.

Em 1922, estalou uma guerra civil no Paraguai que, inicialmente, enfrentou facções diferentes do partido liberal, basicamente nucleadas em governistas - cujos referentes eram Eusebio Ayala e Eligio Ayala e schaeristas - liderados pelo parlamentar Eduardo Schaerer. À instabilidade política - traduzida na sucessão de vários presidentes em um curto período de tempo -, somou-se o enfrentamento armado que contou também com a participação de setores do exército e do Partido Colorado. A guerra estendeu-se até o ano seguinte e, para Caballero Aquino, o trunfo dos governistas levou à submissão do exército ao poder civil, o que seria um antecedente para o golpe de 1936 que daria fim à

${ }^{10}$ Nas primeiras cartas é revelado que esta prática era veiculada através do jornal partidário Pátria. Mas, a partir da criação da Editorial de Índias, González se propus escrever ensaios sobre O’Leary, Moreno, López Decoud e Domínguez para aqueles que "queiram conhecer a formação de nossa cultura", numa clara promoção do grupo de intelectuais revisionistas (carta de González a O’Leary, de 03/02/1924). 
era liberal e à paulatina aproximação dos oficiais ao Partido Colorado (CABALLERO AQUINO, 2013).

Naquele ano de 1922, O’Leary morava em Assunção e González lhe sugeria insistentemente para que abandonasse a cidade e se estabelecesse em Buenos Aires. González ainda era solteiro e oferecialhe sua casa até que, após alguns meses trabalhando na Monte Domecq - onde lhe garantia um posto de trabalho -, pudesse chamar sua família.

Desta maneira, González poderia retribuir toda a generosidade de O'Leary enquanto ele era um desconhecido, além do reconhecer sua importância central nas mudanças ideológicas da década de 1920 no Paraguai. Num tom alentador, concluía que os dois "poderíamos ganhar muito dinheiro para, algum dia, voltar a nossa terra para que o senhor possa colher os frutos de sua grande campanha" (carta de González a O’Leary, de 08/07/1922).

À preocupação com O’Leary, agregava-se a de informar sobre as atividades desenvolvidas pelos intelectuais lopiztas que transitavam ou moravam em Buenos Aires, como uma maneira de mostrar seu compromisso com o grupo de pares.

Além dos intelectuais paraguaios e europeus, González teve especial cuidado de visitar alguns intelectuais portenhos, vinculados a O'Leary e precursores do revisionismo histórico argentino, como Ernesto Quesada e David Peña. Se bem González não o explicitou, o estilo da escrita sugere que uma das indicações de O'Leary ao chegar em Buenos Aires foi a de procurá-los (carta de González a O’Leary, de 26/08/1922).

Em 1922, a Argentina era governada pelo radical Hipólito Yrigoyen que tentou implementar medidas que marcaram certa diferenciação com os governos anteriores, mais conservadores, em relação à política internacional. Uma delas foi muito bem recebida por estes intelectuais lopiztas e foi o projeto apresentado ao congresso argentino de perdão e supressão da dívida do Paraguai pela Guerra da Tríplice Aliança (ESCUDÉ e CISNEROS, 2000). González, admirador do dirigente radical, obteve um artigo de Quesada sobre este tema, que foi publicado no jornal Pátria (cartas de González a O'Leary, de 02/09/1922 e de 29/11/1922). 
Se bem ao longo de sua estadia em Buenos Aires também manteve contato com intelectuais de outros países latino-americanos, foi a partir de 1923 que manifestou um interesse especial por se vincular aos mexicanos, vislumbrado a possibilidade de publicar além das fronteiras rio-platenses. ${ }^{11}$

Tais ações demonstram a preocupação de González em se autopromover e são indícios de uma incipiente construção de uma imagem de si para a posteridade. Ou seja, ele é, nessa fase de sua vida, o escritor que não mede esforços para dar a conhecer ao mundo a "verdadeira" história e a beleza de seu Paraguai, ao mesmo tempo em que se mostra como um intelectual e um militante preocupado com a imagem de seu mestre.

Diante da extensão da guerra de 1922, que se prolongou por vários meses, surgia um González crítico dos governos liberais, mas também sensibilizado pela existência de "medíocres que dominam e dilaceram o país” (carta de González a O’Leary, de 03/06/1922). Em agosto daquele ano, avaliava as terríveis consequências do conflito como:

[...] las horas terribles que vivimos son como para conmover a cualquiera... Claro que venceremos al fin a la mala suerte, y que los malos hijos no conseguirán nunca lo que no logró el conquistador estrangero...; vamos a padecer mucho... el hambre se sebará en nuestro pueblo, tan digno de mejor suerte... Esta última calaverada de los liberales va a legarnos una deuda que no podremos pagar (carta de González a O’Leary, de 07/08/1922).

Em outubro do mesmo ano, reforçava seus argumentos sobre o devir pós guerra, mas explicitando um posicionamento político favorável aos intelectuais, desenhando um projeto político para si:

Sigo con intensa amargura los episodios de nuestra guerra civil. No me entusiasma ni uno ni otro bando... Triunfe quien triunfe, los males causados al país serán inmensos. Y así seguiremos mientras no se conceda prioridad a los intelectuales sobre los políticos... lo que da personería, significación ideal a las naciones, son sus pensadores y sus artistas (carta de González a O’Leary, de 31/10/1922).

\footnotetext{
${ }^{11}$ González manifestou seu interesse em viajar até o México para publicar seu último livro, após o incentivo do diplomata Enrique González Martínez quem teria lhe oferecido introduzi-lo no mundo literário de seu país (carta de González a O’Leary, de 21/03/1923).
} 
Este era o objetivo principal para Natalicio González. Quando ele fazia uso de sua "pluma" para recriar "nossa vida camponesa, tão cheia de beleza e poesia" não representava só um ato de criação estética. Era também um ato político. Daí a necessidade de promover o grupo de intelectuais ao qual pertencia e, muito particularmente, o seu líder, Juan O'Leary:

Pude haber creado algo mientras otros destruyen lo poco que tenemos... Le hago partícipe de esta íntima satisfacción mía, ya que a usted le debo tanto, casi todo lo que soy. Este es otro aspecto de su personalidad que nadie ha puesto de relieve todavía: usted ha mantenido viva la llama de la espiritualidad, el amor a las letras, en un medio hostil a las manifestaciones del intelecto, salvando del naufragio muchas nobles y desinteresadas vocaciones juveniles (carta de González a O’Leary, de 31/10/1922). ${ }^{12}$

A promoção da figura de O'Leary dava legitimidade ao grupo de jovens escritores que o secundavam, como o próprio González. E aqui a luta política, nessa fase da vida de Natalicio González, adquiria outro matiz: o da renovação da velha guarda pelos mais jovens.

Para o jovem Natalicio, na década de 1920, a renovação da história ia atrelada à renovação dos "velhos" pelos "jovens" - entre os quais incluía-se - na política nacional, nos quadros dirigentes do Partido Colorado e nas autoridades das associações de paraguaios no exterior, como o Centro Paraguaio de Buenos Aires (cartas de González a O'Leary, de 26/04/1922; de 03/06/1922; de 26/08/1922; s/d e de 21/03/1923).

Segundo González, houve um grave choque entre dois grupos que pretendiam controlar a direção deste último, identificados genericamente como "velhas múmias" e as "jovens promessas". Para González, sua participação na vida interna do Centro Paraguaio em Buenos Aires era de fundamental importância para sua efetiva inserção política não só no interior da coletividade paraguaia, senão também

12 "Eu consegui criar enquanto outros destroem o pouco que temos... Lhe participo desta íntima satisfação porque devo muito ao Senhor, praticamente tudo o que eu sou. Este é um aspecto de sua personalidade que ninguém tem salientado ainda: o Senhor tem mantido viva a chama da espiritualidade, o amor pelas letras, num meio hostil às manifestações do intelecto, salvando do naufrágio muitas nobres e desinteressadas vocações juvenis" (carta de González a O’Leary, de 31/10/1922). 
diante da sociedade argentina ao se apresentar como principal representante de sua comunidade:

Hemos llevado un recio ataque al Centro Paraguayo con éxito completo, batiendo el reducto en que se defendían los Rebaudi. Yo soy ahora el secretario. Los viejos... llevaron las cosas en los tribunales pero acabamos de obtener un fallo a nuestro favor... $\mathrm{Y}$ es que hasta ahora los bandos en lucha en ese Centro no buscaban realizar nada que pueda prestigiar el nombre de nuestro país. Querían lucrar sencillamente.

Yo tengo grandes proyectos que estoy por realizar. Quiero inaugurar una exposición permanente de productos paraguayos y además editar una gran revista mensual de historia y letras, donde se publicará una sección de documentos históricos y traducciones de libros raros sobre el Paraguay... Cuento con el apoyo de Morenito y espero contar también con el suyo (carta de González a O’Leary, de 1922). ${ }^{13}$

Se as atividades literárias e editoriais eram, indiretamente, atividades políticas, a participação nas organizações associacionistas dos paraguaios na Argentina era seu cartão de apresentação na política nacional paraguaia. Ocupar os lugares chaves da política no Paraguai e no exterior era feito a partir da desqualificação que deslegitimava os outros sob epítetos de velhos, múmias, gagás, incompetentes. Dita desqualificação era um mecanismo para tentar deslocar do poder - em suas diferentes instâncias - a um grupo político (os liberais) e substituílo por outro (colorados revisionistas).

Ser representante de sua coletividade foi o passaporte de González para se inserir na cosmopolita Buenos Aires, espaço por excelência para a socialização de muitos intelectuais latino-americanos. Nas décadas de 1920 e 1930, era o espaço urbano que nucleava intelectuais e publicações como nenhum outro na América do Sul. Por esta razão, a

13 “Assestamos um duro ataque ao Centro Paraguaio com total sucesso, acabando com o reduto no qual se refugiavam os Rebaudi. Agora, eu sou o secretário. Os velhos... levaram o assunto para a a Justiça, mas esta se pronunciou ao nosso favor... Até agora, os bandos enfrentados nesse Centro nada fizeram que pudesse prestigiar o nome do nosso país. Simplesmente queriam lucrar.

Eu tenho grandes projetos para realizar. Quero inaugurar uma exposição permanente de produtos paraguaios e também editar uma revista mensal de história e letras, na qual se publicará uma seção de documentos históricos e traduções de livros raros sobre o Paraguai... Tenho o apoio de Moreninho e espero contar com o seu também. (carta de González a O’Leary, de 1922). 
Monte Domecq decidiu se trasladar até a capital argentina, e foi ali que González começou a gestar seu projeto editorial autônomo.

A cidade oferecia os meios técnicos, de divulgação e circulação necessários para o crescimento e expansão de editoras de menor porte como as paraguaias. Porém, González observava diferenças qualitativas profundas no modo de vida paraguaio e o portenho, salientando as saudades e a superioridade espiritual de sua terra.

González preocupava-se em mostrar o que se fazia em Buenos Aires enviando livros e revistas para O'Leary - em muitas cartas mencionava o envio de exemplares das revistas Caras y Caretas e Fray Mocho, nas quais teria publicado (carta de González a O’Leary, de 02/09/1922). Porém, os benefícios materiais da grande "Cartago" - aludindo a Buenos Aires - não compensavam a distância da "superioridade de nosso pequeno país” (carta de González a O’Leary, de 26/04/1922). Para González, a capital argentina era o lugar "onde todos estão empenhados na busca do ouro, é onde a gente sente uma desoladora solidão... Há mais espiritualidade na nossa terra mártir" (carta de González a O’Leary, de 03/02/1924).

Mostrar-se com saudades e acreditar na superioridade espiritual do Paraguai eram também estratégias de mostrar seu compromisso com o país. Assim, em cada palavra, em cada gesto, em cada ação, González revelava-se um intelectual interessado em incursionar na vida política nacional a partir de uma perspectiva ideológica que buscava revisitar a história com o objetivo de recuperar o poder para o partido colorado. A escrita - em todas suas formas: biográficas, ensaísticas, jornalísticas, etc. - fazia parte desse projeto político.

De que modo Natalicio González pensava levar adiante este projeto? Com quais recursos poderia afrontar a mobilidade por vários países, a criação e funcionamento de uma editora, dedicar tempo para a criação literária? Nas cartas dirigidas a O’Leary, só é mencionado que os fundos seriam fruto de anos de trabalho - de muito trabalho, como é enfatizado em várias cartas - na Monte Domecq, o que teria permitido poupar o suficiente para iniciar sua empresa editorial.

A sua produção intelectual estava ligada a seu esforço sistemático e disciplinado, ao ponto de não duvidar em tirar horas de sono em prol da leitura e do trabalho criativo (carta de González a O’Leary, de 
11/06/1921). Assim, construía a imagem de si como autodidata e estudioso disciplinado. Se há reiteradas referências ao "trabalho intenso", não acontece o mesmo com a origem dos recursos, exceto vagas alusões.

Há um aspecto pessoal que chama a atenção nas cartas de González para O’Leary. Em uma delas, mencionava a situação pela qual teriam atravessado uma irmã e seu marido, cuja casa teria sido invadida e saqueada durante a guerra de 1922. González referia-se a este fato para denunciar a responsabilidade dos liberais. Porém, nenhum de seus biógrafos mencionou a existência de irmã/s mulher/es. ${ }^{14}$

A falta de concordância entre alguns elementos desta escrita de si do Natalicio jovem e as biografias publicadas quando Natalicio González era um ex-presidente exilado evidencia os silêncios de seus biógrafos e dele mesmo em relação a dados vinculados à sua família (pais, irmãos, sobrinhos). Por alguma razão, esta irmã foi silenciada nas biografias, assim como os parentes restantes teriam desaparecido rapidamente e sem descendência. ${ }^{15}$

Ao silenciar aos diferentes integrantes da família de González se fortalece a ideia de um homem que se fez sozinho, sem a ajuda e sem obstáculos por parte de familiares, exceto em raras ocasiões como as em que o pai teria ajudado economicamente o filho em algumas circunstâncias, ou em que os irmãos teriam iniciado Natalicio na leitura dos clássicos e, no final de sua vida, quando um sobrinho - cujo nome nunca é revelado - teria contribuído ao desaparecimento da biblioteca e do arquivo, provas materiais da vida intelectual de Natalicio González. Não aparecem outros parentes próximos - aparentemente todos desaparecidos quando da morte de González - e aqueles parentes que surgem são, além de anônimos, parentes distantes de modo tal que não chegariam a ensombrecer a figura de Natalicio González.

\footnotetext{
14 Em uma das cartas, González fazia referência "às irmãs", no plural (cartas de González a O’Leary, de 07/08/1922 e de 02/09/1922).

${ }^{15}$ Em relação a sua esposa, Lydia, só há uma menção breve nas missivas para enviar seus cumprimentos a O'Leary e a sua esposa (Carta de González a O’Leary, de 01/08/1927). Questionado, Enríquez Gamón respondeu rapidamente e com total desinteresse que os irmãos de Natalicio González tinham falecido antes dele. González só teria um sobrinho, filho de uma prima, que na hora do decesso de González morava no México e teria sido o autor do roubo do arquivo e da biblioteca de seu tio (Entrevista a Efraín Enríquez Gamón, por Marcela Cristina Quinteros).
} 
Nas últimas cartas, a partir de dezembro de 1924, "Natalicio" passou a assinar como "Natalicio González", assinatura que manteria em outros documentos posteriores. A proximidade e o distanciamento dados pelo vínculo de amizade intelectual com seu mestre se manteria, mas o personagem Natalicio tinha ganho nome e sobrenome para empreender seu caminho por si.

A autonomia e o prestígio construídos por Natalicio González eram tais que Juan O'Leary considerava seu discípulo como um amigo e uma referência das letras paraguaias. Em julho de 1927, O’Leary comunicava a González que tinha obtido o reconhecimento da Academia da Língua no Paraguai, por parte da Real Academia Espanhola, integrada, entre outros, por Natalicio González (carta de O’Leary a González, de 05/07/1927). Isto era de fundamental importância para O'Leary, considerando-o um trunfo que permitiria o reconhecimento do Paraguai no universo da língua espanhola.

Porém, dois meses mais tarde, o apreço por González como um igual se manifestou em um tom de tristeza misturado com pinceladas de decepção e de reconciliação, colocando em evidência as tensões da relação epistolar:

Su carta es una fiesta para mí. Hace un siglo que suspiro por sus noticias. Su absoluto silencio me tenía triste, amargado, porque yo solo sé lo que lo quiero y no podía comprender su indiferencia. A todos los amigos - a Ritter en todas mis cartas - les he pedido que pidieran que me escribiera, que, por lo menos, me contestara mis cartas. Y los meses pasaban sin un recuerdo suyo... Por fin me da la piadosa satisfacción de escribirme. Estoy contento (Carta de O'Leary a González, de 12/09/1927). ${ }^{16}$

O'Leary confirmava a troca intelectual e a reciprocidade de favores, ao mesmo tempo em que felicitava seu "querido y recordado Natalicio" pelo "formoso artigo" publicado no jornal espanhol El Sol que, para O'Leary, somados aos artigos de outros intelectuais paraguaios, ajudariam a construir conceitos favoráveis do país.

16 "Sua carta é uma festa para mim. Há um século que suspiro por notícias suas. Seu absoluto silêncio deixou-me triste, amargado, porque só eu sei o quanto o aprecio e não conseguia compreender sua indiferença. Tinha solicitado a todos os amigos especialmente a Ritter, em todas as cartas - para que lhe lembrassem de me escrever ou, pelo menos, respondesse às minhas cartas. Mas os meses passavam sem uma lembrança sua. Agora estou contente" (Carta de O’Leary a González, de 12/09/1927). 
Nesta mesma carta, O’Leary mencionava a organização da viagem de González para a Europa, provavelmente, referindo-se à viagem de bodas que faria com sua esposa Lydia Frutos. A pesar de ser o responsável dos assuntos diplomáticos do Paraguai em Madri, O’Leary decidira morar em Paris, mais barata e menos solitária, rodeado de "paraguaios, da minha tertúlia e sou completamente feliz. Se o senhor vier, me encherá de alegria" (carta de O’Leary a González, de 12/09/1927).

Pelo documento, observa-se que a relação entre ambos intelectuais ia além do binômio mestre-discípulo. O’Leary mostrava grande afeto e reconhecimento por González, aprovando quase todas suas ações tais como, a publicação de artigos em jornais de diferentes países, a atividade editorial - confiando-lhe a primeira edição de um livro seu pela Editorial de Índias - e a "tendência de os senhores dentro de nosso partido", numa clara mostra de apoio a suas iniciativas políticas. O'Leary só manifestava certo incômodo quando reiterava a falta de notícias do "recordado Natalicio" e ao resgatar a importância de sua nomeação como membro da "Real Academia Espanhola da Língua", assunto sobre o qual González não teria se manifestado.

Deste modo, O'Leary deixava a impressão de que o discípulo tinha ganho tal autonomia de criação e ação que teria superado a necessidade de render uma constante reverência a seu mestre, o que explicaria as interrupções e tensões no contato epistolar. Não ter comentado sobre sua nomeação como membro da Academia de Letras, pode indicar, talvez, que as prioridades para González passavam mais pelo campo político e não tanto pelo seu reconhecimento como "homem de letras".

\section{Considerações Finais}

É possível observar as três temporalidades (passado, presente, futuro) na troca epistolar entre Juan Natalicio González e Juan Emiliano O'Leary. O presente do jovem Natalicio era um presente cheio de novidades e projetos para o futuro imediato. Era um presente que abria diversas portas para o futuro, seja por meio da editora, da política, da ensaística ou do jornalismo.

O passado era resgatado em duas dimensões. Uma mais recente, para se referir às ações políticas de colorados - enxergados como inovadores - 
e de liberais - vistos como conservadores; a outra dimensão era mais remota, para trazer os "heróis" do século XIX ao seu presente. O jovem Natalicio apresentava-se como um jovem escritor e empreendedor, preocupado com o passado e com um futuro imediato de seu país, momento da ação para a mudança. E ele era o fator da mudança enquanto um jovem intelectual colorado.

Esta fonte permite identificar a crescente autonomia de González em relação a O'Leary durante a década de 1920, o que teria sido facilitado pela sua alta auto-estima quanto pela sua inserção no mundo literário, editorial e político de Buenos Aires. Isto teria aberto as portas para o mundo, ou seja, para o universo literário e editorial parisiense. Ambas experiências favoreceram o regresso de um Natalicio González maduro, um escritor e editor de certo prestígio e com a bagagem política necessária para assumir a condução do partido e liderar o grupo de parlamentares que lutaram pela reivindicação de Solano López em todos os níveis durante as décadas de 1920 e 1930.

\section{Referências}

BENÍTEZ, L. G. Breve Historia de Grandes Hombres. Assunção: Gráfica Comuneros, $1986 . \quad$ Disponível em: http://www.portalguarani.com/975_pablo_max_ynsfran.html. Acessado em: 11/10/2015.

BREZZO, Liliana. Juan E. O'Leary. El Paraguay convertido en acero de pluma. Assunção: El Lector, ABC Color, 2011.

. "El historiador y el general: imposiciones y disensos en torno a la interpretación pública de la historia en Paraguay". In: Revista Nuevo Mundo, Mundos Nuevos, Questões do tempo presente, Dezembro de 2014. Disponível em: https://nuevomundo.revues.org/67479?lang=pt Acessado em: 23/09/2015.

CABAllero AQUINO, R. La Guerra Civil de 1922. Assunção: ABC Color-El Lector, 2013.

ESCUDÉ, C. e CISNEROS, A. Historia General de las Relaciones Exteriores de la República Argentina. Buenos Aires: Consejo Argentino para las Relaciones Exteriores, 2000. Tomo VII, Cap. 38: Las 
relaciones con Paraguay. Disponível em: http://www.argentinarree.com/7/7-082.htm. Acessado em: 07/10/2015.

GOMES, Ângela de Castro (Org.). Escrita de si, Escrita da História. Rio de Janeiro: FGV, 2004.

PIGLIA, Ricardo. O último leitor. São Paulo: Companhia das Letras, 2006.

SERVÍN GAUTO, R. (Org.). Forjadores del Paraguay. Assunção: Aramí, 2001. In:

http://www.portalguarani.com/2079_ramon_monte_domecq.html (consultado em 23/09/2015).

\section{Fontes}

ADEP. Representantes Diplomáticos Paraguayos. Assunção: ADEP, 2011 .

ASHWELL, Washington (Org.). El homenaje a J. Natalicio González largamente esperado. Assunção: Cuadernos Republicanos, 2004.

ENRÍQUEZ GAMÓN, E. La guerra inconclusa. Esquema para una ideología nacional. Assunção: Litocolor, 1982.

Yo y mi sombra, o El cazador de Luciérnagas. Assunção: Servilibro, 2012.

ENTREVISTA a Efraín Enríquez Gamón, por Marcela Cristina Quinteros, Assunção, 09/09/2015.

GONZÁlEZ, Juan Natalicio. Vida y Pasión de una ideología. Assunção: NAPA, 1982.

Cartas a J. E. O'Leary. In: Arquivo da Biblioteca Nacional do Paraguai, Coleção Juan E.O’Leary (1920-1927).

GONZÁleZ Y CONTRERAS, G. J. Natalicio González. Descubridor del Paraguay. Assunção: Guarania, Biblioteca Paraguaya, 1951.

O’LEARY, Juan Emiliano. Cartas a J. N. González. In: Arquivo da Biblioteca Nacional do Paraguai, Coleção Juan E.O’Leary (1920-1927). 
Recebido em 09/11/2015

Aceito em 30/12/2015

Revista Ambivalências • ISSN 2318-3888 • V.3 • N.6 • p. 90 - 114 • Jul-Dez/2015. 